\title{
Correction to: Modification of the third phase in the framework for vertebrate species persistence in urban mosaic environments
}

\author{
Colleen T. Downs ${ }^{(1)}$, Jarryd Alexander, Mark Brown, Moses Chibesa, Yvette C. Ehlers Smith, \\ S. Thobeka Gumede, Lorinda Hart, Kyrone K. Josiah, Riddhika Kalle, Machawe Maphalala, \\ Mfundo Maseko, Shane McPherson, Samukelisiwe P. Ngcobo, Lindsay Patterson, Kerushka Pillay, \\ Cormac Price, Islamiat Abidemi Raji, Tharmalingam Ramesh, Warren Schmidt, Ntaki D. Senoge, \\ Tinyiko C. Shivambu, Ndivhuwo Shivambu, Nikisha Singh, Preshnee Singh, Jarryd Streicher, \\ Vuyisile Thabethe, Harriet Thatcher, Craig Widdows, Amy-Leigh Wilson, Manqoba M. Zungu, \\ David A. Ehlers Smith
}

Published online: 21 April 2021

Correction to: Ambio

https://doi.org/10.1007/s13280-021-01501-5

In the original publication, the Fig. 2 was processed incorrectly during the typesetting and publication process. The correct Fig. 2 is provided in this correction.

The original article has been corrected.

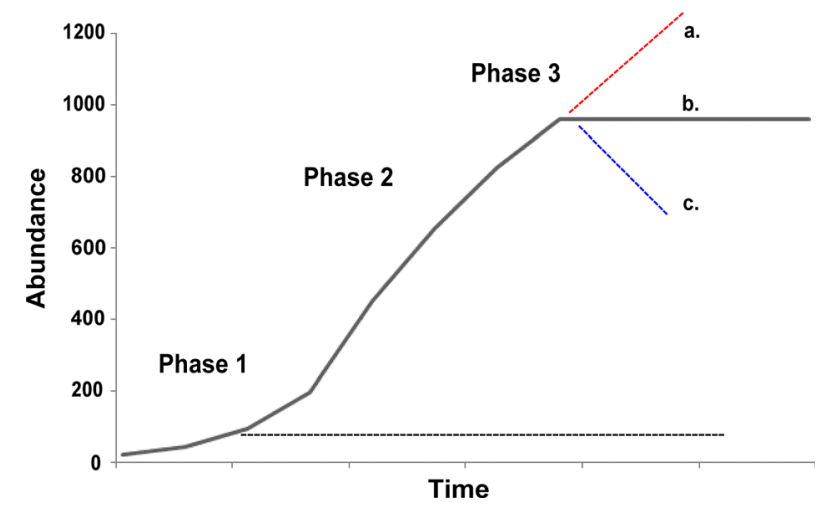

Fig. 2 Summary of the three phases for respective herptile, mammalian and avian species persistence and abundance in urban areas of KwaZulu-Natal, South Africa (modified from Evans et al. 2010). This highlights for species that increase, that in phase 3 species can either (a) continue to increase (red dotted line), (b) plateau, or (c) decline (blue dotted line) with time. Note that black dotted line in phase 1 is typical of species that persist in suburbia albeit being in low numbers and typically are not exceptional urban exploiters

The original article can be found online at https://doi.org/10.1007/ s13280-021-01501-5.
Publisher's Note Springer Nature remains neutral with regard to jurisdictional claims in published maps and institutional affiliations.

Colleen T. Downs $(\square)$

Address: Centre for Functional Biodiversity, School of Life Sciences, University of KwaZulu-Natal, Scottsville, P/Bag X01, Pietermaritzburg 3209, South Africa.

e-mail: downs@ukzn.ac.za

Jarryd Alexander

Address: Centre for Functional Biodiversity, School of Life Sciences, University of KwaZulu-Natal, Scottsville, P/Bag X01, Pietermaritzburg 3209, South Africa.

e-mail: jarryd1004@gmail.com

\section{Mark Brown}

Address: Centre for Functional Biodiversity, School of Life Sciences, University of KwaZulu-Natal, Scottsville, P/Bag X01, Pietermaritzburg 3209, South Africa.

e-mail: brownma@ukzn.ac.za

\section{Moses Chibesa}

Address: Centre for Functional Biodiversity, School of Life Sciences, University of KwaZulu-Natal, Scottsville, P/Bag X01, Pietermaritzburg 3209, South Africa.

e-mail: moses.chibesa@gmail.com

Yvette C. Ehlers Smith

Address: Centre for Functional Biodiversity, School of Life Sciences, University of KwaZulu-Natal, Scottsville, P/Bag X01, Pietermaritzburg 3209, South Africa.

e-mail: yvetteehlers@yahoo.com

\section{S. Thobeka Gumede}

Address: Centre for Functional Biodiversity, School of Life Sciences, University of KwaZulu-Natal, Scottsville, P/Bag X01, Pietermaritzburg 3209, South Africa.

e-mail: thobekagumede123@gmail.com 


\section{Lorinda Hart}

Address: Centre for Functional Biodiversity, School of Life Sciences, University of KwaZulu-Natal, Scottsville, P/Bag X01, Pietermaritzburg 3209, South Africa.

e-mail: rinjordaan@gmail.com

\section{Kyrone K. Josiah}

Address: Centre for Functional Biodiversity, School of Life Sciences, University of KwaZulu-Natal, Scottsville, P/Bag X01, Pietermaritzburg 3209, South Africa.

e-mail: kyronekentjosiah@gmail.com

\section{Riddhika Kalle}

Address: Centre for Functional Biodiversity, School of Life Sciences, University of KwaZulu-Natal, Scottsville, P/Bag X01, Pietermaritzburg 3209, South Africa.

e-mail: riddhikalle@gmail.com

\section{Machawe Maphalala}

Address: Centre for Functional Biodiversity, School of Life Sciences, University of KwaZulu-Natal, Scottsville, P/Bag X01, Pietermaritzburg 3209, South Africa.

e-mail: machawe158@gmail.com

\section{Mfundo Maseko}

Address: Centre for Functional Biodiversity, School of Life Sciences, University of KwaZulu-Natal, Scottsville, P/Bag X01, Pietermaritzburg 3209, South Africa.

e-mail:mst.maseko@gmail.com

\section{Shane McPherson}

Address: Centre for Functional Biodiversity, School of Life Sciences, University of KwaZulu-Natal, Scottsville, P/Bag X01, Pietermaritzburg 3209, South Africa.

e-mail: shane.mcpherson@gmail.com

\section{Samukelisiwe P. Ngcobo}

Address: Centre for Functional Biodiversity, School of Life Sciences, University of KwaZulu-Natal, Scottsville, P/Bag X01, Pietermaritzburg 3209, South Africa.

e-mail: sam.p.ngcobo@gmail.com

\section{Lindsay Patterson}

Address: Centre for Functional Biodiversity, School of Life Sciences, University of KwaZulu-Natal, Scottsville, P/Bag X01, Pietermaritzburg 3209, South Africa.

e-mail: lindsayleighpatterson@outlook.com

\section{Kerushka Pillay}

Address: Centre for Functional Biodiversity, School of Life Sciences, University of KwaZulu-Natal, Scottsville, P/Bag X01, Pietermaritzburg 3209, South Africa.

e-mail: kerushka@gmail.com

\section{Cormac Price}

Address: Centre for Functional Biodiversity, School of Life Sciences, University of KwaZulu-Natal, Scottsville, P/Bag X01, Pietermaritzburg 3209, South Africa.

e-mail: priceco@tcd.ie

\section{Islamiat Abidemi Raji}

Address: Centre for Functional Biodiversity, School of Life Sciences, University of KwaZulu-Natal, Scottsville, P/Bag X01, Pietermaritzburg 3209, South Africa.

e-mail: abiraj4success@gmail.com

\section{Tharmalingam Ramesh}

Address: Centre for Functional Biodiversity, School of Life Sciences, University of KwaZulu-Natal, Scottsville, P/Bag X01, Pietermaritzburg 3209, South Africa.

e-mail: ramesh81ngl@gmail.com

\section{Warren Schmidt}

Address: Centre for Functional Biodiversity, School of Life Sciences, University of KwaZulu-Natal, Scottsville, P/Bag X01, Pietermaritzburg 3209, South Africa.

e-mail: warren@biodiversitynature.com

Ntaki D. Senoge

Address: Centre for Functional Biodiversity, School of Life Sciences, University of KwaZulu-Natal, Scottsville, P/Bag X01, Pietermaritzburg 3209, South Africa.

e-mail: ntaki.senoge@gmail.com

\section{Tinyiko C. Shivambu}

Address: Centre for Functional Biodiversity, School of Life Sciences, University of KwaZulu-Natal, Scottsville, P/Bag X01, Pietermaritzburg 3209, South Africa.

e-mail: shivambucavin@gmail.com

\section{Ndivhuwo Shivambu}

Address: Centre for Functional Biodiversity, School of Life Sciences, University of KwaZulu-Natal, Scottsville, P/Bag X01, Pietermaritzburg 3209, South Africa.

e-mail: ndivhuwomaligana@gmail.com

\section{Nikisha Singh}

Address: Centre for Functional Biodiversity, School of Life Sciences, University of KwaZulu-Natal, Scottsville, P/Bag X01, Pietermaritzburg 3209, South Africa.

e-mail: nikishasingh555@gmail.com

\section{Preshnee Singh}

Address: Centre for Functional Biodiversity, School of Life Sciences, University of KwaZulu-Natal, Scottsville, P/Bag X01, Pietermaritzburg 3209, South Africa.

e-mail: preshnee.singh@gmail.com

\section{Jarryd Streicher}

Address: Centre for Functional Biodiversity, School of Life Sciences, University of KwaZulu-Natal, Scottsville, P/Bag X01, Pietermaritzburg 3209, South Africa.

e-mail: jarrydstreicher@gmail.com

\section{Vuyisile Thabethe}

Address: Centre for Functional Biodiversity, School of Life Sciences, University of KwaZulu-Natal, Scottsville, P/Bag X01, Pietermaritzburg 3209, South Africa.

e-mail: thabethevuyisile@yahoo.com

\section{Harriet Thatcher}

Address: Centre for Functional Biodiversity, School of Life Sciences, University of KwaZulu-Natal, Scottsville, P/Bag X01, Pietermaritzburg 3209, South Africa.

e-mail: thabethevuyisile@yahoo.com

\section{Craig Widdows}

Address: Centre for Functional Biodiversity, School of Life Sciences, University of KwaZulu-Natal, Scottsville, P/Bag X01, Pietermaritzburg 3209, South Africa.

e-mail: craig@malachitesa.co.za 


\section{Amy-Leigh Wilson}

Address: Centre for Functional Biodiversity, School of Life Sciences, University of KwaZulu-Natal, Scottsville, P/Bag X01, Pietermaritzburg 3209, South Africa.

e-mail: wilsonamyleigh@gmail.com
David A. Ehlers Smith

Address: Centre for Functional Biodiversity, School of Life Sciences, University of KwaZulu-Natal, Scottsville, P/Bag X01, Pietermaritzburg 3209, South Africa.

e-mail: ehlerssmithd@ukzn.ac.za

\section{Manqoba M. Zungu}

Address: Centre for Functional Biodiversity, School of Life Sciences, University of KwaZulu-Natal, Scottsville, P/Bag X01, Pietermaritzburg 3209, South Africa.

e-mail: zungumm@gmail.com 